\title{
Nursing Competency as Experienced by Hospital Nurses in a Clinical Nursing Unit
}

\author{
Hye-Won $\mathrm{Kim}^{1}$ and Mi-Ran Kim ${ }^{2 *}$ \\ ${ }^{1,2}$ Konyang University, College of Medicine, Department of nursing, Daejeon, Korea \\ ${ }^{1}$ hwkim@konyang.ac.kr, ${ }^{2}$ mrkim@konyang.ac.kr
}

\begin{abstract}
The present study used Colaizzi's descriptive method to understand the nature and meaning of nursing competency in a clinical nursing unit. As a result, the meanings of nursing competency as experienced by hospital nurses were found to be as follows: "nursing qualifications developed through nursing tasks," "time invested to become a true nurse," "work performance fulfilled by a satisfactory desire," "positive results yielded by an effortful process of providing outstanding nursing care," "qualifications as a nurse realized by educational efforts," "realizations of positive interactions through learning and process," "qualifications as a nurse realized by accumulating nursing work experience," "colleagues that understand each other and provide strength," and "experience of oneness with the patient during the caring process." Consequently, it is necessary for nursing managers and hospital organizations to precisely understand the meaning and level of nursing competency for nurses and to provide program support to enhance nurses' performance.
\end{abstract}

Keywords: Nurses, Hospitals, Nursing competency

\section{Introduction}

Nursing competency is basic nursing performance requirement [1] in a clinical setting and describes the capacity to integrate and apply skill, knowledge, and decision for a particular nursing task [2]. Furthermore, it is possible to make actual observations of nursing competency, as it is a behavior that exhibits high performance results.

The improvement of nursing competency has an influence on the job satisfaction of nurses as well as qualitative patient care. Furthermore, nursing competency has been identified as an important precedent factor that positively influences [3] the productivity of nurses by facilitating the formation of harmonious relationships with other departments and managing the transfer rate of the nursing work force.

Consequently, it is necessary to precisely confirm the nature of nursing competency to elicit successful nursing results and raise the nursing performance expectations of the organization. Base on the above confirmation process, nursing capacity should be properly defined and its result computed.

\footnotetext{
* Corresponding Author: Mi-Ran, Kim

Department of Nursing, College of Medicine, Konyang University

158 Kwanjeodong-ro, Seogu, Daejeon, Rep. of Korea 302-832

Tel: +82-42-600-6346 FAX: +82-42-600-6314 E-mail: mrkim@konyang.ac.kr
} 
Furthermore, the selection, education, guidance, and evaluation of the nursing workforce should lead to the systematic improvement of nursing competency exhibited within the hospital.

To date, precedent studies have only advocated for the necessity of nursing competency measurement tools, measurement results, and development; in-depth studies that investigate the experience and nature of nursing competency as a unique subjective phenomenon occurring in the nursing field are insufficient [4].

As such, the present study investigated the nature and meaning of nursing competency as experienced by a hospital nurse at a clinical nursing unit to precisely grasp the substantive reality of the terminology. The present study is believed to provide basic data to create a nursing work environment wherein individual nurses can fully exercise the nursing competency expected from their respective clinical units and acquire professionalism to effectively perform nursing tasks.

\section{Methods}

\subsection{Study Design}

The study used Colaizzi's descriptive method [5] in order to understand the nature and meaning of nursing competency in a clinical unit.

\subsection{Sampling and Data Collection}

The study participants were six veteran nurses from six different locations, including Seoul, Gyeonggi-do, and Daejeon, who understood and experienced the meaning of clinical nursing competency. All of the participants were female with an average age of 32.6 and average work experience of 7.3 years. Data were collected between March 1, 2011, and August 30, 2011, through semi-structured individual in-depth interviews. The primary question posed in the in-depth interview was, "What is the nature and meaning of nursing competency as experienced by a hospital nurse in a clinical unit?" All of the interviews were conducted in the participants' workplace or neighborhood. The duration of the interviews was between a minimum of 60 minutes and a maximum of 2.5 hours.

Table 1. Characteristics of the Participants $\quad(\mathrm{N}=6)$

\begin{tabular}{ccc}
\hline & Category & $\mathrm{n}(\%)$ \\
\hline Age (years) & $26-30$ & $2(33.3 \%)$ \\
Gender & $31-35$ & $4(66.7 \%)$ \\
& Female & $6(100.0 \%)$ \\
Marital status & Male & $0(0.0 \%)$ \\
& Unmarried & $4(66.7 \%)$ \\
Educational status & Married & $2(33.3 \%)$ \\
Clinical experience & Bachelor & $4(66.7 \%)$ \\
(years) & Master & $2(33.3 \%)$ \\
& $\leq 1$ & \\
& $2-5$ & $2(33.3 \%)$ \\
& $\geq 5$ & $4(66.7 \%)$ \\
\hline
\end{tabular}




\subsection{Ethical Consideration}

The study purpose and reporting as well as the recording of the interview contents were explained in detail. The participants were promised the protection of their rights and personal information.

\subsection{Data Analysis}

The present study used the data analysis method presented by Colaizzi (1978). After conducting the in-depth interviews, the transcribed interviews were read repeatedly, and any statements that were directly relevant to the phenomenon were extracted.

\section{Results}

The nature and meaning of nursing competency as experienced by hospital nurses were found to make up a total of nine factors: "nursing qualifications developed through nursing work," "time invested to become a true nurse," "work performance fulfilled by satisfactory desires," "positive results yielded by an effortful process of providing outstanding care," "qualifications as a nurse realized through educational efforts," "positive interactions realized through learning and process," "qualifications as a nurse realized through the accumulation of work experience," "colleagues that understand and give strength to one another," and "experiencing oneness with the patient during the caring process".

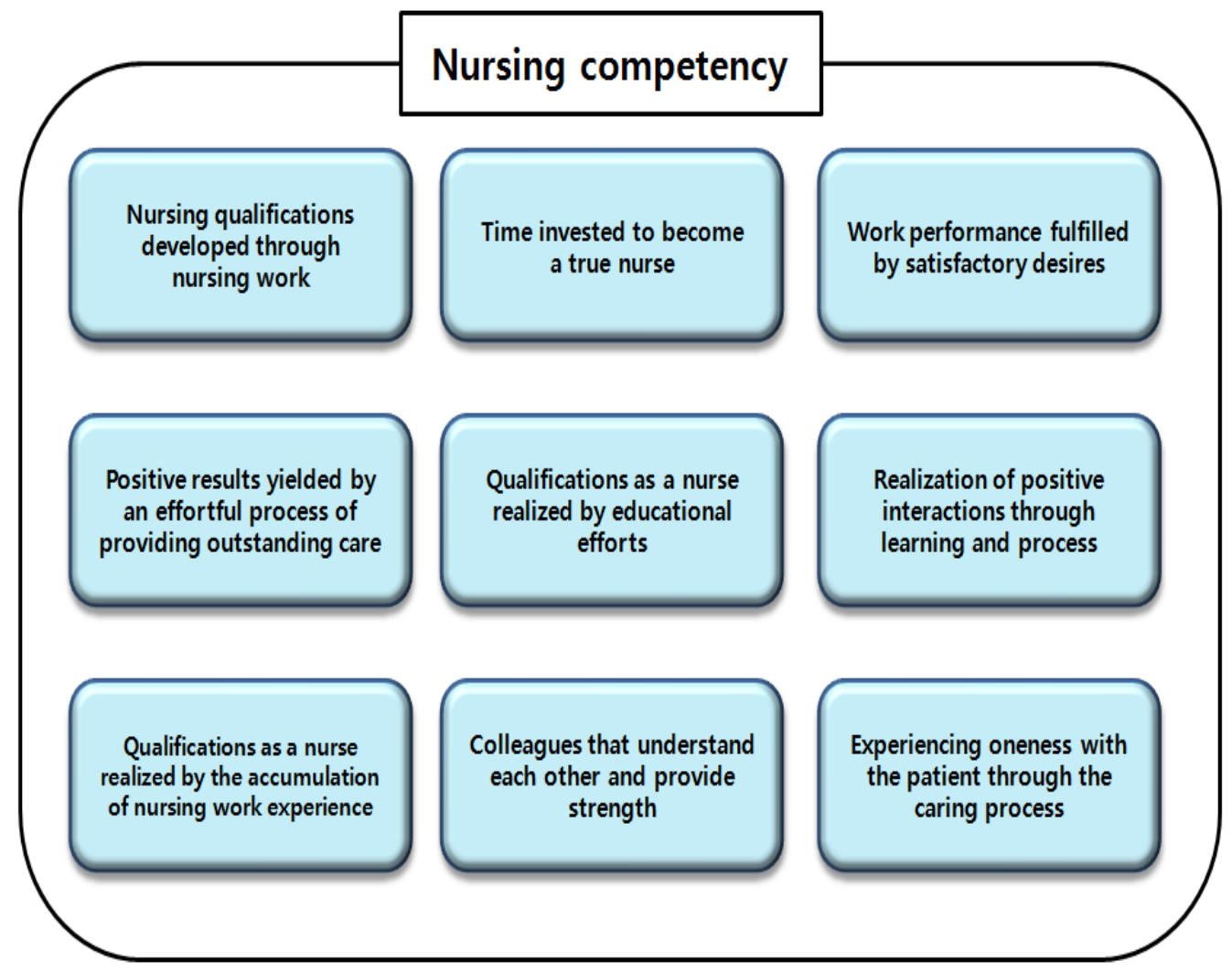

Figure 1. Nursing Competency as Experienced by Hospital Nurses: Topic Collection 


\section{Category 3.1. Nursing Qualifications Developed through Nursing Work}

\subsubsection{Topic collection. Existence of instances in which the value of nursing work is} realized:

When an emergency situation was resolved and the patient revived, I felt like a very important person, especially when the families remember me and are grateful for my service. (Participant A)

\subsubsection{Topic collection. Occupational attraction of nursing work:}

Usually, when patients are discharged from the hospital, we say, "please don't come back to the hospital again." The feeling of letting go of patients restored to health, mixed with a bit of regret, is the best and most rewarding feeling. (Participant $\mathrm{C}$ )

\subsubsection{Topic collection. Realization of harmonious relationships with other people:}

I think I showed good nursing practice when I promptly prepared supplies, revived the patient and looked after the family and guardian of the patient all at once, satisfying myself, the patient, the family, as well as other medical professionals involved. (Participant E).

\section{Category 3.2. Time invested to become a true nurse}

\subsubsection{Topic collection. Starting nursing without an accurate idea about the true nature} of the work:

I think I had not truly comprehended the importance of nursing except through some clinical training, although I always thought I knew the importance of nursing, which I was going to pursue for the rest of my life. (Participant F)

\subsubsection{Topic collection. Realization of efforts to uphold principles:}

I think nurses should be aware of the latest nursing practice and be able to form a rapport with the patients. (Participant C)

\subsubsection{Topic collection. Efforts to remember the original passion for the work:}

The busier I am, the more I try to remember the initial passion I had. Remembering that skipping a procedure will not shorten your work time and the possibility of my family member being hospitalized and receiving the same kind of nursing care makes me rethink my actions. (Participant A)

\subsubsection{Topic collection. Retroactive capacity based on the accumulation of nursing work experience and efforts:}

When I put in more effort to explain certain examination, injection or surgical procedures in detail, patients and their families show more appreciation, making me want to work even harder. (Participant E) 
3.2.5. Topic collection. The meaning of nursing discovered by providing the best care possible for the patient:

In the past, I had to go up and down the stairs from the fourth floor to the twelfth floor, trying to get emergency medication. With the effort, I was relieved to see the patient in a better state, and the patient was very grateful to see me physically running around to get him the medication, which resulted in building a foundation of trust. The patient and I were both satisfied by this experience. (Participant D)

\section{Category 3.3. Work performance fulfilled by satisfactory desires}

\subsubsection{Topic collection. Rejuvenation of strength through the recovery of the patient:}

Most nurses feel rewarded by experiencing the recovery of patients and realize the value of working in a hospital despite the hard work. (Participant C)

\subsubsection{Topic collection. Nursing qualifications developed through long clinical experience} and learning:

One nurse told me she almost felt afraid because her premonition of patients' health statuses ended up being true. I think this is an "intuition" of an experienced nurse, which is part of the abilities of a nurse developed through clinical knowledge and experience with many patients. (Participant F)

\subsubsection{Topic collection. Experiencing the occupational appeal of nursing through positive} nursing experiences:

Patients without a guardian show much gratitude for brief attention from or helping hand of a nurse. Seeing them getting better makes me feel that I am an important person doing important work! (Participant A)

\section{Category 3.4. Positive results yielded by a diligent process of providing outstanding care}

3.4.1. Topic collection. Receiving assistance with regard to nursing work by utilizing individual strengths:

An extroverted personality lets you build closer relationships and establish rapport with patients more easily. (Participant D)

\subsubsection{Topic Collection. Exertion of individual effort to provide prompt and precise care:}

When I first started working, I was really terrified and afraid of the fact that small mistakes and immaturity put patients in irreversible danger. I always studied and tried to remember everything after I got home from work. (Participant B)

\section{Category 3.5. Qualifications as a nurse realized through educational efforts}

\subsubsection{Topic Collection. Necessity of effort and understanding to train future nurses:}

There is a need to lead and train the new nurses well, so that they can undergo as little trialand-error learning as possible and become independent and proactive nurses as soon as possible. 


\section{Category 3.6. Positive Interactions Realized through the Learning Process}

\subsubsection{Topic Collection. Necessity of communication process within the context of a} harmonious relationship:

In a hospital, we are working not only with patients and their families, but also with many other medical professionals. Nursing becomes easier when everyone who works together gets along. (Participant E)

\subsubsection{Topic Collection. Strength Developed through Consistent Cognition and Efforts:}

A patient treated by different nurses shows different results, reaction, and compliance, depending on who trains and provides nursing care to the patient. (Participant B)

\subsubsection{Topic Collection. Realization during the Learning Process through Role Models:}

There are experienced nurses who are great role models, but occasionally there are some who are not very educational. Hence, it is important to find a good role model. (ParticipantF)

\section{Category 3.7. Qualifications as a Nurse Realized through the Accumulation of Work Experience}

\subsubsection{Topic Collection. Becoming Committed to a Patient-Centered Care:}

First of all, there should not be a work-related error, so that when accuracy in work and prompt communication with the patients lead to good resolution, there is effective nursing performance. (Participant D)

3.7.2. Topic collection. Becoming more prepared by predicting and making decisions beforehand:

In the case of a patient with dressing, giving them a painkiller 30 minutes before changing the dressing according to the PRN prescription, rather than after they undergo pain, will allow the patient to be treated comfortably. (Participant F)

\subsubsection{Topic collection. Qualifications and capacities of a nurse realized through nursing} work:

All sorts of things happen in a hospital, but they do not always happen when a chief nurse or an experienced nurse is around. We always need someone who can mediate and resolve a complicated situation. (Participant B)

\subsubsection{Topic collection. Trying to provide peace to the patient in the caring process:}

You do not need to meet every demand of the patients but you need to be able to calm them down by carefully listening to them and attending to their physical discomforts, followed by an accurate decision. (Participant F) 


\section{Category 3.8. Colleagues that understand and give strength to one another}

\subsubsection{Topic collection. Heartfelt emotional connection among colleagues:}

The bond between nurses might even be stronger their bonds with families that live a distance away. The comfort I gain from a quietly helping hand and an understanding glance when I am overwhelmed by overflowing work is paramount. (Participant E)

\subsubsection{Topic collection. Group cohesiveness grounded on the emotional connection among colleagues:}

When I have a shift the day after, I feel at ease when I can ask about the condition of the patients to the nurse who was on the previous shift, establishing interest and understanding between each other.

\section{Category 3.9.: Experiencing oneness with the patient during the caring process}

\subsubsection{Topic collection. Experiencing oneness with the patient by understanding the patient:}

Let us not judge patients and their families, even when they are being unreasonable to a point that is beyond our understanding. Even if we cannot understand them, we cannot treat them the same way as other healthy people. (Participant D)

\subsubsection{Topic collection. Experiencing and advocating the patient-centered approach through nursing work:}

Through working, I came to realize why nurses are known as protectors. Other medical professionals, especially doctors, only put focus on the physical aspects of the patients. The power and ability to represent everything about the patients and guide them the right way is the nature of nursing work. (Participant A)

\section{Discussion and Conclusion}

This study showed that the clinical nursing abilities experienced by nurses were categorized as the following four aspects and nine categories: 1) Interpersonal aspects, such as colleagues who empower and understand each other. 2) Individual aspects, such as work performance satisfactory to the individuals, positive results yielded by a diligent process of providing outstanding care, and the realization of positive interactions through a learning process. 3) Work aspects, such as nursing qualifications developed through nursing work, time invested to become a true nurse, qualifications as a nurse realized by the accumulation of nursing work experience, and experiencing oneness with the patient through the caring process. 4) Educational aspects, such as qualifications as a nurse realized by educational efforts [11].

In addition, to improve nursing abilities, professional knowledge and personal abilities need to be developed. Further, the improvement of the nursing environment and reevaluation of the roles and functions of nurses need to be accomplished, ultimately leading to improvements at the legal and institutional levels [8-10]. 


\section{Table 2. Nursing Competency as Experienced by Hospital Nurses: Topic} Collection

\begin{tabular}{|c|c|c|}
\hline number & topic collection. & topic \\
\hline 1 & $\begin{array}{l}\text { Nursing qualifications } \\
\text { developed through } \\
\text { nursing work }\end{array}$ & $\begin{array}{l}\text { 1) Existence of instances in which the } \\
\text { value of nursing work is realized } \\
\text { 2) Occupational attraction of nursing } \\
\text { work } \\
\text { 3) Realization of harmonious } \\
\text { relationships with other people }\end{array}$ \\
\hline 2 & $\begin{array}{c}\text { Time invested to become } \\
\text { a true nurse }\end{array}$ & $\begin{array}{l}\text { 1) Starting nursing work without an idea } \\
\text { about the true nature of the work } \\
\text { 2) Realization of efforts to uphold } \\
\text { principles } \\
\text { 3) Efforts to remember the first passion } \\
\text { of the work } \\
\text { 4) Retroactive capacity based on the } \\
\text { accumulation of nursing work experience } \\
\text { and efforts } \\
\text { 5) The meaning of nursing discovered by } \\
\text { providing the best care possible for the } \\
\text { patient }\end{array}$ \\
\hline 3 & $\begin{array}{l}\text { Work performance } \\
\text { fulfilled by satisfactory } \\
\text { desires }\end{array}$ & $\begin{array}{l}\text { 1) Rejuvenation of strength through the } \\
\text { recovery of the patient } \\
\text { 2) Nursing qualifications developed } \\
\text { through long clinical experience and } \\
\text { learning } \\
\text { 3) Experiencing occupational attractions } \\
\text { of a nurse through positive nursing } \\
\text { experiences }\end{array}$ \\
\hline 4 & $\begin{array}{l}\text { Positive results yielded } \\
\text { by an effortful process of } \\
\text { providing outstanding } \\
\text { care }\end{array}$ & $\begin{array}{l}\text { 1) Receiving assistance with regard to } \\
\text { nursing work by utilizing individual } \\
\text { strengths } \\
\text { 2) Exertion of individual effort to provide } \\
\text { quick and precise care }\end{array}$ \\
\hline 5 & $\begin{array}{l}\text { Qualifications as a nurse } \\
\text { realized by educational } \\
\text { efforts }\end{array}$ & $\begin{array}{l}\text { 1) Necessity of effort and understanding } \\
\text { to train future nurses }\end{array}$ \\
\hline 6 & $\begin{array}{l}\text { Realization of positive } \\
\text { interactions through } \\
\text { learning and process }\end{array}$ & $\begin{array}{l}\text { 1) Necessity of communication process } \\
\text { within the context of a harmonious } \\
\text { relationship } \\
\text { 2) Strength developed through consistent } \\
\text { cognition and efforts } \\
\text { 3) Realization through the learning } \\
\text { process through role models }\end{array}$ \\
\hline
\end{tabular}


Qualifications as a nurse realized by the accumulation of nursing work experience

8

9
1) Becoming committed to patientcentered care

2) Becoming prepared by predicting and making decisions beforehand 3) Qualifications and capacities of a nurse realized through nursing work 4) Trying to provide peace to the patient in the caring process

1) Heartfelt emotional connection among colleagues

2) Group cohesiveness grounded on the emotional connection among colleagues

1) Experiencing oneness with the patient by understanding the patient

2) Experiencing and advocating for the patient-centered approach through nursing work

\section{References}

[1] International Council of Nursing. An implementation models for the ICN framework of compentencies for generalist nurse. Standards and competencies series (2nd ed.). Geneva: ICN. (2003).

[2] B. Campbell \& G. Mackay, "Continuing competence: An Ontario nursing regulatory program that supports nurses and employers", Nursing admission Quartey, vol. 25, no. 2, (2001), pp. 22-30.

[3] J. Choi, The character of the nursing organizational culture and organizational effectiveness. Unpublished doctoral dissertation, Korea University, Seoul. (2003).

[4] R. Meretoja, H. Isoaho \& H. Leino-Kilpi, "Nurse competency scale Development and psychomertic testing", Journal of Advanced Nursing, vol. 47, (2004), pp. 124-133.

[5] P. F. Colaizzi, "Psychological research as the phenomenologist views it", In R. S. Valle \& M. King(Eds.), Existential phenomenological alternatives for psychology. New York, NY: Oxford University Press. (1978)

[6] M. Eraut, "Competencies As a Concept and Tool for Regulation", Keynote speech, The 5th International on the Regulation of Nursing and Midwifery, Cofenhagen, Denmark. (2001).

[7] H. W. Kim, M. R. Kim, "The Nature and Meaning of Nursing Competency as Experienced by Hospital Nurses", Advanced Science and Technology Letters, (2014), April 47; Jeju, Korea.

[8] S. J. Kim, M. S. Choi, K. W. Sung, "Variables Affecting Competency of Nurses in Nursing Homes", J Korean Gerontol Nurs, vol. 12, no. 1, (2010), pp. 29-39.

[9] J. K. Ko, M. S. Chung, M. A. Choi, Y. I. Park, K. S. Bang, J. A. Kim, M. S. Yoo, H. Y. Jang, "Modeling of Nursing Competencies for Competency-Based Curriculum Development", The Journal of Korean academic society of nursing education, vol. 19, no. 1, (2013), pp. 87-96.

[10] K. S. Jang, "A Study on Establishment of Clinical Career Development Model of Nurses”, Unpublished Doctoral thesis, Yonsei University, Seoul. (2000).

[11] Y. H. Chang, Y. S. Cho, M. J. Kwak, "A Study of Factors Related Nursing Competency in Nurses”, Journal of Korean Clinical Nursing Research, vol. 12, no. 1, (2006), pp. 7-19. 
International Journal of Bio-Science and Bio-Technology

\section{Authors}

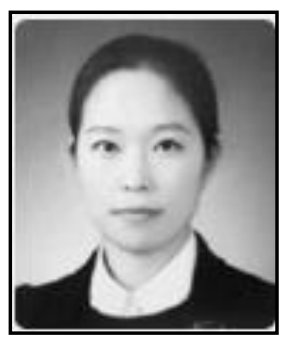

\section{Hye-Won Kim}

Feb. 2012: Seoul National Univ. PhD.

Aug. 2010 - Current: Konyang Univ. Professor

Research Interests: Chronic Kidney Disease, Biobehavioral factor

E-Mail: hwkim@konyang.ac.kr

\section{Mi -Ran Kim}

Feb. 2012: Korea Univ. PhD.

April. 2010 - current: Konyang Univ. Professor

Research Interests: Nursing Competency, Patient Safety

E-Mail: mrkim@konyang.ac.kr 